\title{
A POESIA NO SISTEMA DE HERÁCLITO
}

Donaldo Schüler

Universidade Federal do Rio Grande do Sul

Résumé

On pourrait s'étonner de l'essal de chercher de la póesie chez un penseur qui a l'habitude d'attaquer les poètes. Toutefois, la compréhension immédiate d'un texte ne décêle pas toujours toute sa vérité. Héraclite offre des ambigüités, des jeux sonores, des créations verbales à effet nettement poétique. II incrimine les lecteurs qui ne sont pas capables de lire les poètes d'une manière convenable et non pas les poètes eux-mémes. L'adresse de sa critique lui permet également de rejeter la poésie sans invention, dégénérée, la poésie qui n'est pas poétique. En distinguant la poésie dégénérée de celle authentique, il rend a la poésie propre un service précieux. Les déroutements de son jugement sont ainsi largement compensés par des observations fécondes. pleines de défi et d’actualité. 
Pode causar surpresa o empenho em procurar poesia num pensador que ataca sistematicamete os poetas. Heráclito năo poupa Homero, Hesfodo, Heráclito e Safo, os melhores então. Nem sempre, entretanto, o entendimento imediato de um texto expбe a verdade inteira. Năo farfamos justiça a Platão, se nos contentássemos com as passagens em que 0 autor da Repáblica bane os poetas. $O$ caráter fragmentário do legado heraclftico requer atenção ainda maior. A auscultação atenta dos escombros de um sistema portentoso poderá levar-nos a achados valiosos. Comecemos com o exame de uma passagem preservada no fragmento 24 , aparentemente sem interesse para a poesia.

Os aresfa (d) (i) ados, deuses os honram $\theta$

homens. (B24)

Queremos, com os parênteses, indicar duplo percurso de leitura: Aresfadados $\theta$ Aresfalados. Entendam-se por Aresfadados os soldados mortos no campo de batalha, dominio de Ares, o deus da guerra. Estes mesmos, epicamente glorificados por seus feitos bélicos, sấo os Aresfalados. O termo grego que originou os neologismos (Aresfadados, Aresfalados) 6 argifatos. $O$ segundo elemento da composiçáo, fatos, pode derivar-se do verbo feml (falar) ou do verbo theino (matar).

A época de Heráclito repele a exaltaçăo da morte e com ela a poesia épica. Para os jônios dos anos 500, năo há bem maior que a vida. Esta comparece glorificada na poesia lírica.

Heráclito, em outros momentos antagonista de Homero, propoe agora, com a leitura de duplo percurso, a manutençăo da poesia guerreira sem abjurar os novos ideais de vida. Fazem injustiça a Homero os que o têm na conta de cantor da morte. Ao glorificar os mortos em combate, ele os mantém no convivio social, perpetuando-lhes a vida. A morte fisica năo é a fatalidade maior. A enfática sociabilidade dos gregos vê, na privaçăo da companhia dos homens, a morte que excede a própria morte. Não se pode considerar completamente morto quem goza da honra dos contos épicos, de ampla circulaçáo nas cidades. A morte năo e total quando o desaparecido convive preservado na fala. Fadados falados testemunham a convergência da vida $\theta$ da morte. Mantenha-se, portanto, simultâneo o duplo percurso.

O romance contemporâneo $\theta$ a epopéla antiga falam de coisas diferentes. O romance fala do que se faz, do limiado, da vida sendo e perecivel. Mesmo quando, como em Proust, o herói se volta ao passado, traça a indefinivel trajetória do seu aniquilamento interior. A epopela, por apresentar do homem a imagem exterior e acabada, cristallza-se em vida plena, redime-o da história $\theta 0$ aproxima dos deuses Imortais. Els a razăo por que o glorificam os deuses. Estes só mantêm em evidência ọ que, como eles, se perpetua. O romance fala do aniqullamento da vida, a epopéla canta a extinçăo da morte. Neste últumo caso, na concepçăo de Heráclito, os heróis participam da morte-vida. A voz das Musas exprime a vontade dos deuses de manter viva a memória dos herbis tombados no campo de batalha. Fala heracliticamente Manuel Bandeira ao dizer:

Duas vezes se morte:

Primelro na carne, depols no nome. 
Os nomes, embora mais resistentes do que a carne, rendem-se ao poder destruidor do tempo como as lápides. Sendo, porém, acolhidos na poesia, os nomes entrentam o desgaste com enérgica robustez, dádiva, na antigüidade, das Musas. Através das Musas, os deuses honram os heróis e săo elas que falam na voz dos poetas.

Se Heráclito considera a poesia lugar adequado ao vigor intemporal dos nomes. como entender a hostilidade do filosofo aos poetas? Devemos acolher a suspelta de que o poeta nåo reprova a poesia quando feita e cultivada autenticamente. Advertidos desta hipotese, submetemos os fragmentos pretensamente antiposticos a exame. Focalizemos com este fim o fragmento 56:

Enganam-se os homens quanto ao conhecimento das colsas manifestas aproximadamente à maneira de Homero, que fol o mais sábio de todos os helenos. Pois esse, os meninos o enganavam, ao matarem os piolhos, dizendo: o que vimos $\theta$ apanhamos, isto largamos, mas o que nåo vimos e nåo apanhamos, isto carregamos. (B56)

O mito privilegia a cegueira. Legendarlamente cego foi Tirésias, divinamente dotado com percepçáo penetrante do que ainda não aconteceu para compensá-lo da cegueira com que fol castigado. Tirésias acerta em Édipo Rei a causa da peste. O outro cego de renome é Homero, mais tanglivel do que Tiréslas, porque delxou dois poemas, básicos na formaçăo dos helenos. A visăo do mundo que Homero impôe, através da instrução, toma-o o mais perigoso dos cegos, eis a razáo porque Heráclito o ataca com tanto rigor.

Mas as invectivas de Heráclito atingem antes os leitores de Homero. Homero năo é responsável pelo mau uso que dele se faz. Năo faltou ao poeta senso crftico nem observaçăo. Ele foi o primeiro a introduzir dúvida fecunda na religiåo transmitida, $\theta$ sua atenta descriçăo dos fenômenos alicerça a preocupaçăo pelo comportamento do mundo.

Os leltores cegos, entretanto, quiseram transformá-lo em porta voz dos deuses. Suas elaboraçס̃es poéticas deveriam ser consideradas objetivamente verdadeiras. A formaçáo assim orientada degenera em deformaçăo, e Heráclito o denuncla. A ceguelra não $\theta$ para o filósofo nenhuma vantagem. Atribulu-se aos cegos a capacidade de resolver enigmas ${ }^{2}$. Para ridicularizar esta noçáo, Herácllto cerca o poeta cego de meninos que brincam com plolhos. Catados e esmagados nas unhas, săo jogados fora. Os outros piolhos prosseguem a viagem, protegidos pela cabeleira.

O que os meninos dizem $\theta$ cegueira para cegos. Ve-se, portanto, que o dicurso se toma enlgmático quando desprendido dos referentes. Os que fazem de Homero criador de enigmas são péssimos observadores. Os enigmas, por năo tolerarem a luz da observaçáo, săo cultivados por cegos, que năo levam nenhuma vantagem sobre as pessoas que enxergam. Condenado Homero como profeta, Heráclito o salva como poeta. Ao atacá-1o, recorre a uma cena do mundo infantll porque nos meninos se incute respelto sacral por Homero. Antt-homérico soa ainda o fragmento 42. 
É claro, o tal Homero deve ser eliminado dos concursos aos golpes e Arqunico também. (B42)

Palavras de um sacrilégio? Enfim, Homero é festejado onde quer que se fale grego. Heráclito, contudo, năo inaugurou a irreverência. Arqufloco já o fizera antes dele, ao modo de outros Irricos. Por thes serem estranhos os ideais épicos do vate por todos idolatrado, os liricos cultivam conflitos interiores. Arqulloco ousa falar de sua próprias fraquezas. A vida the vale mais que a honra. Para salvála, abandona o escudo ao intmigo. Degradou a guerra ao nivel das profissరes assalariadas. Dedica-se a ela para ganhar o păo. E é só.

Entretanto, a linguagem desinibida de Arqufloco năo contribul para construir o discurso que acolhe as divergencias. $O$ poeta, ao levantar armas contra um sistema, isola-se em outro. Em nome do pensamento dialético, Heráclito ataca a épica $\theta$ a lirica com igual vigor. Enquanto Homero se perde no inventário de coisas, Arqulloco se afunda na subjetividade. Não há razão para preferências.

A critica do pensador beneficiou a poesia. Os concursos promovem a competiçăo de excelências. Privada de força crftica, a obra acolhida nos concursos definha nos altares da admiraçăo. A desvirilizaçăo năo fere apenas os autores consagrados, desgasta com igual inércia poetas recentes como Arqunloco. Tomados clássicos, os versos tomam-se património da classe de prestigio. Demitidos do papel de sujeito, os versos passam a circular como objetos inertes ao sabor das manipulaçర̋es. No interesse do vigor da obra, convém arrebatar os poetas da classe que os desativa nos concursos. Golpeados e expulsos, falarăo no deserto contra os que buscam o conforto dos lugares seguros. Como todo discurso, a poesia se revigora no jogo da contestaçăo. $O$ louvor petrifica com os olhos da Medusa por reduzir o estranho à banalidade familiar. Năo compreendida, a poesia revolve a segurança cotidiana, instalando o mistério no territorio que se julga dominar.

Os leltores competentes, desinteressados em saber quem 6 o maior, buscam na poesia revelaçố negadas a outros sistemas. A contradiçăo devolve aos poetas a energia que o othar admirado thes tomou. $O$ que pensa Heráclito do cultor de mitos, Hesfodo? Do consagra autor da Teogonia diz:

Mestre da maioria é Heslodo. Este, pensam, sabe mais. Năo conhece, entretanto, dia e nolte, pois såo uma coisa só. (B57)

No fervor anti-escolar $\theta$ anti-dogmático, Heráclito se excede. Negar a Heslodo conhecimento adequado do dia $\theta$ da noite provoca a suspelta de afirmaçắo apaixonada. Nos atos inaugurais da Teogonia, a Noite gera o Dia, o que sugere a distinçăo apenas aparente de seres iguais na essência. Heráclito deve estar pensando numa passagem da segunda parte do poema, em que Noite $\theta$ Dia jamais freqüentam juntos a superffcie da Terra nem se recolhem, ao mesmo tempo, no abrigo subterråneo. Mas isto náo anula a unicade funamental de infcio estabelecida. 
O que, porém, interessa de fato a Heráclito é desalojar Heslodo da cadeira de mestre em que a cegueira dogmática o instalou. Venerado como autoridade inconteste, Heslodo prejudica, mesmo que acerte. Sendo a observação a base do conhecimento autêntico, requerem remoção as camadas cristalizadas ente o sujeito e o objeto.

Diz a respeito de Safo:

Não vês... quanta beleza têm os cantos sáficos, que encantam e seduzem os ouvintes? A Sibila, entretanto, com boca delirante, proferindo palavras sem risos, sem adomos e sem perfumes nos atravessa com voz de mil anos, amparada pelo deus. (B92)

O que nessa passagem é heráclitico? Quase nada. Para os mais rigorosos apenas "A Sibila com boca delirante". Seja. Cremos, porém, que o comentário de Plutarco, a quem devemos a citaçăo, preservas flexరes dignas de apreço.

A guerra aos poetas atinge agora o requinte da elaboração textual, que deu relevo a Safo. À sonoridade dos versos escritos Heráclito prefere as palavras rudes da Sibila, voltadas exclusivamente ao conteúdo. O comentário ignora o fato de a Sibila consagrada a Apolo falar também em versos. Instituldos pelo próprio filosofo de Éfeso, recusamos a exclusão. Não aceitamos a altemativa Safo ou Sibila. Reconhecida a oposição, preservamos ambas, como o fazemos com as oposiçőes dia-noite, guerra-paz, fome-saciedade... Bafejado por Pitágoras, que triunfará em Platão, Heráclito privilegia. em certos momentos, a razão em detrimento do corpo, infiel ao seu próprio sistema. Se a razão nos desvenda o que se retrai para além dos sentidos, por que, em nome dela, condenar ritmos, assonâncias $\theta 0$ velado baile dos versos? A leitura atenta do espólio de Heráclito revela, de resto, muitos lugares em que a poesia, com rara felicidade, invade a prosa. É graças à poesia que os saborosos diálogos de Platăo resistiram à corrosão dos séculos.

A aceitaçáo simultânea de Safo e Sibila nos permite viver na convergência da razăo e dos sentidos, do oculto e do manifesto, do mistério $\theta$ da luminosidade, da seriedade e do riso, do imorredouro e do perecivel.

O que recrimina, enfim, Heráclito nos poetas? O dogmatismo. Mas este se encontra mals nos leitores do que nos poetas.

A poesia tem a mesma origem da filosofia e do mito: o espanto (thauma), o olhar admirativo para. O olhar para, por se mudarem continuamente quem olha $\theta$ para 0 que olha, conserva viva e não-dogmática a poesia. A poesia resulta endurecida pelos admiradores, por aqueles que tornaram a poesia clássica. Combatendo os receptores e náo os poetas, Heráclito nobilita a poesia, ao contrário do quee se poderia supor. Sendo comum a origem da filosofia $\theta$ da poesia, os limites entre uma $\theta$ outra não se mantêm claros. Preocupaçóes do pensamento filosófico animam também a poesla.

Octavio Paz intitula um dos seus ensaios sobre poesia $O$ arco $\theta$ a lira. $\dot{E}$ claro que o tfulo the vem deste fragmento: 
Não entendem que o diferente condiz consigo mesmo: harmonia discordante como do arco $\theta$ da lira. (B51)

Não é certo que a trasferência da comparação para um livro sobre poesia teria a aprovaçáo de Heráclito, já que o filossofo trata com muita aspereza um lírico da projeção de Arqulloco. Mesmo assim, o livro poderia desperta-lhe interesse, visto que Octavio Paz encontra na lifica o que Heráclito the recusa. O mexicano elabora para a lirica sugestiva teorla dialetica. Segundo ele, contrariamente à prosa, a poesia tem a possibilidade de afirmar simultaneamente 0 sim $\theta 0$ năo. Sendo a ambiçăo da poesia dizer a realidade toda, sem perder nada, ficaria aquém dos seus objetivos lugar alheio a contradiçסes. Enquanto o discurso lógico as exclul, a poesia as cultiva. Por esse caminho, a poesia e a filosofia convergem, mostrando-se a poesia mais filosófica do que muitos tratados.

Estranha convergência a do arco e da lira. Recorre-se áquele na guerra, esta soa em momentos de paz. Como todas as exclusóes absolutas, também esta náo é mais do que aparente. Os soldados manejam o arco para alcançar a paz, ao passo que os poetas celebram, ao som da lira, façanhas guerreiras.

Percebe-se que a oposiçăo de Heráclito à poesia não é tão absoluta como dá a entender quando combate supostos radicalismos nos poetas. Trazida a poesia, como aqui, para o discurso com-um (syn-on), definham os motivos que o levaram a rejeitála. Octávio Paz compreendeu bem o filósofo, năo se deixando intimidar por ataques ostensivos.

A exploraçăo do significado năo contoma as oposiçőes no plano do significante. Tanto 0 arco como a lira operam na tensăo de forças contrárias, $\theta$ estamos autorizados a estendê-las ao ritmo no trabalho e no texto poético. Damos, entåo, fundamento ontologico ao que, de outro modo, derivaria para um initeligivel formalismo.

Em syniasin (entendem), flexăo verbal de syn-hiemi (enviar conjuntamente, entender) convergem forças contrárias. Juntos andam o saber e o năo-saber. $O$ saber progride na companhla do năo-saber, vitalizando-se na contradição. Tanto a visáo meridianamente clara como a ignorância absoluta, por excederem a contradiçăo, fogem da órbita do pensamento.

A tensăo dos opostos compreende a polaridade do saber e do não-saber operante no texto poético. Todo esforço de dizer se embaraça na trama do indizivel. A voz, que soa ao embalo do nitmo, arrasta consigo o silencio, ventre sombrio de todos os possiveis. A palavra gera o seu próprio diferente que mantém retesado 0 arco das significaçбos. A lira deixaria de soar, se a paz entre os opostos chegasse, um dia a ser assinada. A noite sustenta 0 dia na contradiçăo.

Todas as coisas conduz o raio. (B64)

Tentemos penetrar nessa miniatura em que as metáforas se concentram. Raio? Será esse o raio da razăo que risca a noite da ignorâncla? De tudo, a razáo demanda o seco, o fogo, em oposiçăo ao aquoso das impressరos sensoriais. 
O verbo, oiakizo (conduzir) convém a carros e barcos. Imaginemos o barco deslizando sobre as ondas na rota que the imprime o timoneiro. Vem a tempestade. $O$ raio atinge $O$ barco. Fazendo- 0 sossobrar, confronta- 0 com 0 abismo, com as profundidades. A visåo năo é a da superficie, do presente, do palpável, do visivel, da existência plena. Eis um naufrágio que ilumina.

O raio nâo ê indiferente à criaçăo art'stica. Diz o poeta Laci Osório:

Arte

tem relâmpagos inexpllcáveis.

Um rab fulminante arrebatará de Édipo o governo de Tebas. A luz fulgurante descida dos céus lluminará a existência naufragada do rei. Sófocles deve aos filősofos a esclarecida interpretaçăo do mito.

O ralo iluminará também os passos de vidas năo trágicas. A descoberta da verdade atravessa, com frequeencia, a mente como um raio. Torna-se claro de repente 0 que obstinadamente se escondia nas trevas da ignorância. As descobertas que marcam o avanço da humanidade aconteceram no estrondo de insuspeitas chispas de luz.

O mito já via no rosto instrumento de poder, por isso o colocou nas máos de Zeus, sáblo condutor de homens e deuses. O deicida Heráclito dá autonomia ao raio. Esse rasga agora poderosamente a noite sem ser vibrado por ninguém. Livre de toda subordinaçăo, o raio se associa ao discurso que, excedendo-nos, ilumina os despertos. Como cintilação da ordem, orienta.

A intellgéncia dos contrários subverte a tranquilla e caótica existência cotidiana. A luz que fulgara nas mentes em momentos privilegiados governa tudo.Serăo raios as nossas breves existências, necessárias para lluminar a terra com luz fugidia? Assim as entende, ao menos, o poeta venezuelano Eugenio Montejo, que na traduçăo de Sérgio Faraco diz assim:

Dura menos um homem que uma vela

mas a terra prefere seu lume

para seguir os passos dos astros.

Dura menos que uma árvore, que uma pedra, anoitece ante 0 vento mais brando e com um sopro se apaga.

Dura menos que um pássaro, que um peixe fora d'água, quase náo tem tempo de nascer, dá umas voltas ao sol e desaparece entre as sombras das horas. e seus ossos de poeira se misturam ao vento.

$E$ no entanto, quando parte, sempre delixa a terra mais clara. 
Pertinentes à poesia săo também as reflexôes de Heráclito sobre o jogo.

O filbsofo ingressa na roda dos que observam os dados que rolam na chăo, lançados por măos hábeis. A paixăo poderá incendiar o olhar de alguns. Năo se esperem grandes paixర̋es como as surpreendidas por Dostoiévski em O Jogador, os que jogam quando arriscam valores apreciáveis, o que não ocorre em corriqueiras distraçðes de aldeia.

Seja como for, paixర̋es năo atraem o filósofo. Onde outros se entregam ao prazer dos sentidos, Heráclito reflete sobre a vida. Habituou-se a explorar o curso do sol, o fluxo das águas $\theta$ a tensão dos opostos. O resultado incerto dos dados apresenta-lhe agora o símbolo dos movimentos da liberdade.

A vida ú um jovem que joga, jogo de dados: do jovem é o reino. (B52)

Além de todos os dados, percebe um dado que ninguém vê, jogado por măo incerta $\theta$ que reina no universo. As observaçōes de Heráclito abrem caminho às recentes associaçðos de liberdade e jogo (ou brinquedo) feitas por Freud, Huizinga, Heiddeger $\theta$ Derrida, passando pelo Lance de Dados, poema em que Malarmé dissolve a rigidez da sintaxe lógico-discursiva no arranjo livre de constelaçס̋es.

Resolvamos, antes de avançar, problemas de tradução.

Em geral, traduz-se pais por criança. Entretanto, como o termo não distingue claramente infáncla $\theta$ juventude, pais designa também 0 adolescente. Exigindo o jogo de dados habilidades mais desenvolvidas, excluidos eståo os primeiros anos de vida. Outras linguas, incluindo o grego, reúnem, num mesmo termo o que nós dividimos em brincar $\theta$ jogar. Isso nos autoriza a traduzir paizo por jogar. Mais acertados estarfamos se disséssemos jogar-brincac. A nossa tradução procura reproduzir as anáforas do original.

Merece registro a introduçăo do jogo num sistema de extrema logicidade como o de Heráclito, presidido por leis cósmicas, responsáveis pela inteligibilidade do todo. Năo houvesse o livre rolar dos dados, compreendido em limites, năo se entenderiam pensamento nem operaçठes livres.

A criança-jovem que brinca-joga reina nas invensరes poéticas, cientficicas e teóricas.

As epopélas, as tragédias e os sistemas surgem do livre rolar dos dados. Sem ele, náo haveria conhecimento do mundo e de nós mesmos. Nenhum ato livre vem desacompanhado de incerteza. Rigor absoluto, so no que funciona mecanicamente, $\theta$ nem dele pode remover-se a incerteza de uma pane sem hora nem dia estabelecidos para acontecer. $O$ jogo gera o novo em associaçరes $\theta$ disposiçסes novas, sem transgredir as leis do sistema. A decadéncia do jogo congela a história.

A criança dirige a exploraçáo do universo, no qual avançamos lentamente, inexperien tes e trópegos. Nessas andanças, a que poderlamos estar presos, se ignoramos tudo, e quem nos garante que as respostas dadas năo procedem de lúcidos enganos? $O$ jogo redime o filosofo de notórios dogmatismos $\theta$ o preserva para a liberdade que se reinaugura em cada vida. 
O risco é menor no jogo | do que na timidez dos precavidos que elegem caminhos há muito trilhados. Estes se estabelecem conformados na derrota antes de ousar o incerto. Destes a vida, voltada ao despertar do novo, se retrai. Chegam, na queda ao aniquilamento que, com a retenção do gesto, queriam retardar. A poesia só germina aos golpes que afrontam a inércia e abrem caminho ao desconhecido. Como se valer de projetos préviamente elaborados na exploraçăo de territorios que náo se conhecem? Jogo é o método dos que transgridem as fronteiras do saber acumulado.

Ouro, os que o buscam, racham multa

rocha $\theta$ acham muito pouco. (B22)

Eis al outro achado poético de Heráclito, entre tantos. Brinca com as palavras como se fossem objetos. Para se fazer poeta, requer-se o sacriffcio da seriedade, caminho ao mundo da criança, ainda não afetada pelas leis que delimitam os possívels do adulto. $O$ filosofo se diverte com a semelhança das formas verbais oryssousi (cavam) e (heuriskousin) (acham). Ignorada a aspiraçăo inicial do segundo verbo e a leve oposiçáo de y $\theta \boldsymbol{i}$ a diferença se reduz a duas letras; $s \quad \boldsymbol{k}$. A presença ou a ausência do $n$ no segundo verbo năo the altera o significado. Procuramos reproduzir o efeito com racham e acham, acrescentando rocha ao jogo para compensar efeitos sonoros como khryson - oligon gen - pollen $O$ jogo provoca a coincidência de achar e rachar. $O$ achar se dá no rachar. (r) achar.

E com essa preciosidade Heráclito combate a poesia - uma parte dela - poesia épica, presença enfática em todos os de sua geração. O pensador hostiliza agora a cautelosa abundância da epopéia. Os poemas homéricos revolvem muita terra (gen) (racham muita rocha), sendo deploráveis, para o gosto de Heráclito, os resultados dessa trabalhosa mineraçăo. Em lugar do discurso caudaloso, o estilista explora novos recursos, atraem-no pequenos fís, o pensamento reduzido a plulas, a frase epigramática.

Todos os que escrevem racham rocha, e os achados que porventura coroam o trabalho ficam muito aquém do esforço investido. A escória se amontoa, $\theta$ diminutas săo, na fusăo, as porçðes de ouro. Heráclito procura reduzir a diferença quantitativa $\theta$ qualitativa entre as palavras $\theta$ a verdade, entre os signos $\theta$ os referentes.

O investlgador sabe que os nomes das coisas nấo sấo nomes próprios, que designam uma colsa só, apresentando-a como $\theta$. Heráclito lida com nomes comuns, năo ligados a nada especificamente. Por serem diferentes das coisas a que se referem, as palavras podem levantar montanhas sem dizer nada ou dizer multo pouco. Plor alnda, os homens que se debatem nos cursos inchados do discurso, stó afastados da verdade pelo tecido verbal que os devia levar a ela. Para que o fundo dos rios apareça, o nfvel das águas precisa balxar.

Combatendo a abundâncla da poesla éplca, Herácllto privllegla a expressắo concentrada, a economia de palavras, praticada por ele e por lírícos, desde Alceu até Joăo Cabral. A rejeiçấo de certo estilo poético năo o tira do âmbito da poesia.

$O$ pendor pela economla verbal do filosofo de Éfeso encontra ressonancia nas 
páginas téricas de Joåo Cabral. Lembrado da seca, o poeta nordestino hostiliza os poemas caudalosos, que destroem as nuances como o estrondo das cheias. Quer o fluxo restabelecido com trabalho lento, como os liletes que vagarosamente ligam uma poça a outra. As poças textuais dispóem-se como fragmentos de um discurso maior que, no seu contrnuo fluir, năo alcança a abundância de algum oceano.

A atençáo critica voltada aos poetas náo é tudo no sistema heraclitico. Heráclito dá à prosa elevaçăo de poesia. Pośtico é o cuidado artesanal investido na elaboraçăo do texto, construldo com antiteses, metáforas, metonímias, anáforas, símbolos... Poéttca $\theta$ a sintese epigramática, fonte fecunda de renovadas significaçóes.

Os fragmentos de Heráclito pertencem aos textos que solicitam a colaboração do lettor. Desafiam como reservatórios de significaçoes adormecidas que, uma vez despertas, demandam acasalamento com outros discasos para a constituiçăo de prole incontrolável.

Da vida reclusa, cercado de asnos, porcos, lama e feno, banhando-se no no e vendo o sol morrer na tarde sonolenta - Heráclito passa as turbulentas festas primaveris. Camponeses pacatos reúnem-se, transtornados, na aldeia. Ébrios de vinho, levantam representaçరes descomunais do falo em homenagem a Dioniso. Observa judiciosamente Heráclito:

- Pois, se não fizessem procissões a Dioniso e não honrassem os genitais com hinos, procederiam despudoramente.

Mas Hades e Dioniso são o mesmo, a quem deliram e exaltam nas Lenéias. (B15)

Em nenhum dos deuses o contraste se declara tăo enfaticamente como em Dioniso. Associado à vida, remove a tristeza, cura enfermidades, desperta o júbilo, anima a dança, oferece riqueza, distribul beneffcios. Associado à morte, $\theta$ deus temido e perseguido, desaparecendo no Lerna, um lago sem fundo que leva ao misterioso mundo das sombras. Violento e o retorno de Dioniso à superficie luminosa. Ninguém lhe resiste. Os celebrantes destroem os que the recusam culto. Eurfpides, numa de suas tragedias mals bem sucedidas, as Bacantes, dramatiza os excessos criminosos das sacerdotizas contra os adversários.

Opensador mantém-se afastado da loucura coletiva. Poe-se a refletir sobre as festes báquicas que periodicamente se repetem. Como entender que pessoas respeitávels exibam nas celebraçóes o sexo que normalmente conservam oculto? Como $\theta$ que os hinos $\theta$ a procissáo festiva altera tåo profundamente o comportamento?

Herácilto tem predileçåo por fenómenos insolitos. Seduzido pelo mistério, , nada The escapa, nem fatos aparentemente absurdos. Interpreta Dioniso como simbolo da convergencla da vida e da morte. O rito báquico exprime o que ele (Heráclito) busca estabelecer teoricamente. Os opostos revelam/unidade fundamental. A vida $\theta$ a morte se conjugam no mesmo deus. ! 
Em Dioniso, a vida brota do fundo misterioso da morte. No bojo cerrado da morte, a vida se desenvolve. O deus do vinho surge com a força da natureza liberta; irracional $\theta$ violenta, quando arrebenta grilhర̋es letais.

O vinho báquico liga-se, pela umidade, ao irracional e à morte, como também abriga o fogo do saber esclarecido. Convém ver nas muitas alusరos à embriaguez e à água a báquica ambigüidade da vida $\theta$ da morte. As águas letais são também geneslacas. Como tais reproduzem o cicto da vida.

A mesma observação vale para o sexo. Este ora se oculta ora se expoe. A ext biçăo $\theta$ o ocultamento descrevem sua contraditória natureza. $O$ que se mostra $\theta 0$ que se esconde é o mesmo membro viril. O sexo oculto está, pela sua inatividade, relacionado com a morte, para tornar-e fonte de vida deverá incendiar-se e se expor. Pode-se, com propriedade, estabelecer paralelismo entre a morte de Dioniso e a letargia do sexo, a ressurreiçăo de Dioniso e a vitalidade do sexo. A semelhança do sexo, Dloniso ora se oculta, ora se manifesta. Vê-se nas cerimónias báquicas que a vida $\theta$ a morte, o oculto $\Theta$ o manifesto, 0 pudor $\theta$ a impudiclcia năo perturbam a unidade.

Se quisermos acompanhar as reflexס̋es de Lacan, diremos que o falo é a falta, $\theta$ o que nos falta. Os devotos a Dionisio năo exibem o pênis e sim um símbolo. Somos levados a observar a diferença entre o pénis, que náo se desprende do corpo, $\theta$ o falo, o simbolo da fecundidade, exibido na procissão. Ganhamos nova oposiçăo: presençaauséncia. O símbolo aponta para o que, ao se mostrar, nos ultrapassa, o fluxo vital que se desdobra em vida e morte. O que os sentidos apanham nos pontos extremos e nas etapas intermediárias, estende-se uno alêm dos sentidos. Os vários discursos săo recolhidos pelo discurso com-um. Deste ausente fala 0 símbolo nas múltiplas associaçбes que desencadeia. Ninguém tem o fab exibido na procissăo, nem homem nem mulher. A existencia nos feriu a todos. Todos convalescemos da ferida original.

Heráclito interpreta o culto dionísico com notável jogo verbal. Note-se a semeIhança entre asma (canto) $\theta$ aidfon (órgăos sexuals masculinos e femininos). O soar do canto corresponde à exibiçăo do sexo. As ressonância verbals englobam a morte. Aides (o reino dos mortos) significa o invisivel. Este significado contamina retroativamente aidion $\theta$ asma. A lingua opera aproxtmaçăo de vida e morte, visivel e invisível, sem excluir o pudor (aidos) em anaidéstata (despudoradamente).

Os malabarismos lingülsticos de Herácilto, mostram inolvidável força postica. O adversário dos poetas faz-se poeta. Mesmo aquil coincidem os contrários. A prosa artistica, inventada por Heráclito para contestar a fascinaçáo da poesia, retorna à vertente rejeltada.

Da mesma sorte, o mito, contestado pelo paladino da razáo, revive no sistema que o desarticula. Na intençáo de preservar os jogos de linguagem, apresentamos segunda traduçáo do mesmo fragmento.

Pois, se náo fizessem procissăo a Dioniso e năo cantassem na fala o falo, cometeriam despudorada falta. Mas o mesmo săo o Fatal e Dioniso, a quem exultam nas Lenélas. 
Observamos a coincidência da poesia, do mito e da filosofia, no ponto de exclusão. A mitologia grega náo morreu, como milhares de outras mitologias, porque se fez poesia e fibsofia. O destino de toda mitologia que se opó a essa dupla e convergente trajetória é morrer sem deixar lápide.

Houve época em que os arquitetos de mentiras se locomoviam impunes. Por serem hábeis, gozavam do favor dos seus, incumbidos que estavam de preservar a herança cultural $\theta$ de conduztla ao futuro. Falavam como se fossem os porta-vozes dos deuses, como se viesse do alto a voz que saltava da alva cerca dos dentes. Cantavam $\theta$ encantavam. Eram os favorecidos das Musas, os vates venerados, os depositários de remotos herolsmos.

Heráclito năo distingue mentira e ficção, invenção e mistificação, criação de mundos apenas possiveis $\theta$ logro. Quer que a linguagem se anule em beneficio do objeto, que a autoridade dos poetas passe à măo dos filosofos. Inventor de nova maneira de pensar e dizer, afronta com intransigência. É a marca dos inovadores.

Importa-lhe responsabilizar os que exercem o poder da palavra. Andam equivocados se pensam que a comunidade os levou a eminências inalcançáveis. A intolerância estigmatiza também os vates. Instaurou-se um tribunal que os julga. Jâ nåo proferem a palavra absoluta. A palavra autoritária deles é submetida ao exame dos que pensam. A idade da palavra única chegou ao fim. Despontou a época do discurso que se realiza na contradiçấo.

Respeitável é o que o mais respeitado conhece, guarda; a justiça, com certeza, apanhará os arquitetos de testemunhas de artimanhas. (B28)

A justiça năo funciona como mecanismo cego. Ela acompanha os que buscam a verdade, mesmo que năo sejam reconhecidos como tais nem venham expressadamente incumbidos pela comunidade para exercer o offcio. O caminho deles é espinhoso e solitário, mesmo assim, indeclinável. 


\section{BIBLIOGRAFIA}

BAKHTIN, Mikhail. Marxismo e Filosofia da Linguagem. Săo Paulo, Hucitec, 1979. BOLLACK, Jean e WEIMANN, Heinz. Héraclite ou la Séparation Paris, Minuit, 1972.

ECO, Umberto. A Estrutura Ausente. São Paulo, Perspectiva، 1971.

FRÄNKEL, Hermann. Wege und Formen Fruhgriechischen Denkens. München, 1960.

FÜHRER, Rudolf. Formproblem-Untersuchungen zu den Reden in der Frūhgriechischen Lyrik. München, Beck, 1967.

GREIMAS, A.J. et alii. Ensaios de Semiotica Postica. São Paulo, Cultrix, 1976.

HILDEBRANDT, Kurt. Frühe Griechische Denker. Bonn, Bouvier, 1968.

HÖLSCHER, Uvo. Anfängliches Fragen. Göttingen, Vanderhoeck \& Ruprecht, 1968.

KRISTEVA, Julia. Semiotike. Paris, Seuil, 1969.

LACAN, Jacques. Ecrits. Paris, Seuil, 1966.

MONDOLFO, Rodolfo. Heráclito. México, Siglo XXI, 1966.

PAZ, Octavio. O Arco e a Lira Rio de Janeiro, Nova Fronteira, 1982.

REINHARDT, karl. Vermaechtnis der Antike Göttingen, Vanderhoeck \& Ruprecht, 1966.

SEGRE, Cesare. Os Signos e Crítica São Paulo, Perspectiva, 1974.

SCHADEWALDT, Wolfgang. Der Aufbau des Pindarischen Epinikion, Darmstadt, Wissenschaftliche Buchgesellschaft, 1966.

SNELL, Bruno. Gesammelte Schriften. Gobttingen, Vanderhoeck \& Ruprecht, 1966.

TODOROV, Tzvetan. Estruturalismo e Poostica. São Paulo, Cultrix, 1971. 